\title{
O TRABALHO EM COOPERATIVAS DE RECICLAGEM DE RESÍDUOS SÓLIDOS: UM ESTUDO DO RECICLA CONQUISTA
}

\author{
The work in solid waste recycling cooperatives: a study of Recicla Conquista
}

\section{El trabajo en cooperativas de reciclaje de residuos sólidos: un estudio del Recicla Conquista}

\author{
Aline Marinho Santos ${ }^{1}$ http://orcid.org/0000-0001-6884-3803 \\ Maria Zilda Dantas ${ }^{2}$ http://orcid.org/0000-0002-2681-7145 \\ Saulo Silva Teixeira ${ }^{3}$ http://orcid.org/0000-0002-9567-2568
}

\footnotetext{
${ }^{1}$ Graduanda em Administração pela UESB-Bahia-Brasil, alinemarinho13@hotmail.com.br

${ }^{2}$ Especialista Mestre em Administração pela UFBA. Professora do DCSA/UESB-Bahia-Brasil mzdantas@ outlook.com.br

${ }^{3}$ Mestrando em Linguística pela UESB. Professor de Administração da FTC e da Uniasselvi-Brasil saulo.uesb@ hotmail.com.br
}

\section{Resumo}

A sociedade urbana consumista da contemporaneidade contribui sobremaneira para o aumento da quantidade de resíduos nas cidades. A maior parte dessa produção é de difícil decomposição. Além disso, o descarte inadequado do lixo tem se despontado como uma problemática passível de análise. Diante disso, a presente pesquisa teve como objetivo analisar a contribuição de uma cooperativa local como agente responsável pela diminuição dos males causados pelo consumismo, além de compreender a sua importância para o cooperado. A partir dos resultados, verifica-se que o Recicla Conquista, apesar de trazer nítidas contribuições para o meio ambiente e para o cooperado, apresenta falhas de autogestão, além de ser pouco contemplado por políticas públicas.

Palavras-chave: Gerenciamento de resíduos. Coleta seletiva. Cooperativismo.

\begin{abstract}
The urban consumer society of contemporaneity contributes greatly to the increase of the amount of waste in the cities. Most of this production is difficult to decompose. In addition, the inappropriate disposal of garbage has emerged as a problem for analysis. Therefore, the present research aimed to analyze the contribution of a local cooperative as an agent responsible for reducing the ills caused by consumerism, in addition to understanding its importance for the cooperative. From the results, it can be verified that the Recicla Conquista, despite bringing clear contributions to the environment and to the cooperative, presents failures of self-management, besides being little contemplated by public policies.
\end{abstract}

Keywords: Waste management. Selective collect. Cooperativism. 


\section{Resumen}

La sociedad urbana consumista de la contemporaneidad contribuye sobremanera para el aumento de la cantidad de residuos en las ciudades. La mayor parte de esta producción es de difícil descomposición. Además, el descarte inadecuado de la basura se ha desencadenado como una problemática susceptible de análisis. En este sentido, la presente investigación tuvo como objetivo analizar la contribución de una cooperativa local como agente responsable de la disminución de los males causados por el consumismo, además de comprender su importancia para el cooperado. A partir de los resultados, se verifica que el Recicla Conquista, a pesar de traer nítidas contribuciones al medio ambiente y al cooperado, presenta fallas de autogestión, además de ser poco contemplado por políticas públicas.

Palabras clave: Gestión de resíduos. Recogida selectiva. Cooperativismo.

\section{Introdução}

A sociedade urbana contemporânea está cada vez mais voltada para o consumismo, comportamento que contribui para o aumento da produção de resíduos nas cidades. A maior parte dessa produção é de difícil decomposição e, apesar de algumas organizações já estarem mudando suas políticas e voltando-se às necessidades ambientais, o processo e a destinação adequada dos resíduos não é tarefa fácil. No entanto, existem ações, como a coleta seletiva, que podem minimizar os danos causados ao meio ambiente, gerar renda e promover a inserção social.

A gestão de resíduos sólidos é de fundamental importância tanto para a sociedade como para o meio ambiente, pois, muitas vezes, o lixo descartado de forma inadequada ocasiona vários impactos negativos, como o aumento do volume dos lixões e/ou aterros, além de problemas ao meio ambiente e à saúde da população.

A coleta seletiva é apenas o primeiro passo para minorar os impactos da ação antrópica sobre o meio ambiente. Oliveira (2016) ressalta que essa prática deve ser implementada pela ótica da responsabilidade compartilhada, pois, para o funcionamento desse instrumento, faz-se necessária a parceria de esforços conjuntos entre poder público, iniciativa privada e a sociedade.

Segundo Zaneti et al. (2006), os resíduos não representam apenas um dividendo ambiental, mas, sobretudo, uma alternativa para alguns excluídos, que enxergam no lixo a única saída para situação de miséria em que vivem. O terceiro setor, a partir do trabalho das cooperativas, resgata de pessoas que trabalhavam em lixões e possibilitam a inserção social e a melhoria da qualidade vida dos catadores, possibilitando, portanto, uma organização no trabalho que, além de melhorar as condições dos catadores, contribuem para o desenvolvimento sustentável. 
No entanto, Strauch e Albuquerque (2008) alertam que tirar pessoas do lixão para colocá-las em uma cooperativa não é simples. É preciso, antes, entender a sua realidade, a sua cultura, história de vida e ter a sensibilidade de perceber a complexidade em alocá-los a outra realidade, já que estavam acostumadas a trabalhar por conta própria, sem horário ou subordinação e, por isso, podem não acostumar a horários fixos, uniformes e regras prescritivas e normativas.

Em Vitória da Conquista, o Projeto da Cooperativa de Catadores Recicla Conquista LTDA. visa, segundo os Princípios das Cooperativas, à inclusão social e econômica dos catadores de materiais recicláveis. Diante da política de erradicação do lixão do município e construção do aterro sanitário, dezenas de famílias ficariam desamparadas. A cidade possui a $6^{\mathrm{a}}$ maior economia da Bahia, apresenta um comércio dinâmico, variados serviços educacionais e de saúde que contribuem para o desenvolvimento desses setores. A Microrregião de Vitória da Conquista é formada por 17 municípios e mais de 346.069 habitantes. Além disso, o município atende a população das cidades circunvizinhas, ocasionando um crescimento populacional e movimentação comercial, o que, consequentemente, determina o aumento do consumo e da produção de resíduos. Tal conjuntura, torna indispensável o trabalho realizado pelos catadores da Cooperativa de Catadores Recicla Conquista LTDA.

Com o intuito de construir uma ponte entre o conhecimento teórico e a observação da realidade a fim de justificá-la, serão descritos os componentes da metodologia desta pesquisa, são eles: caracterização da pesquisa, unidade de análise, instrumentos de coleta e análise dos dados.

A presente pesquisa pode ser considerada teórico-empírica, pois apresenta modelos teóricos, a partir da revisão da literatura, que se relacionam com a pesquisa de campo. Além disso, trata-se de um estudo descritivo e exploratório. De acordo com Gil (1996), as pesquisas exploratórias têm como objetivo proporcionar maior familiaridade com o problema, com vista a torná-lo mais explícito ou a construir hipóteses; tem como objetivo principal o aprimoramento de ideias ou a descoberta de intuições. Já as pesquisas descritivas objetivam a descrição das características de determinada população ou fenômeno ou, então, o estabelecimento de relações entre variáveis (GIL, 1996).

Esta pesquisa ocorreu por meio de um estudo de caso. Para Gil (1996, p. 58), “o estudo de caso é caracterizado pelo estudo profundo e exaustivo de um ou de poucos objetos, de maneira que permita o seu amplo e detalhado conhecimento, tarefa praticamente impossível mediante os outros delineamentos considerados". 
Tendo em vista que a população é em torno de 40 cooperados, optou-se por fazer uma pesquisa por amostragem probabilística e entrevista semiestruturada. Assim, para a população de 40 cooperados, foram aplicados questionários com 25 , representando uma amostra probabilística de $62,5 \%$ da quantidade total.

Foram utilizados o questionário e a entrevista como instrumentos de coleta de dados. O primeiro, direcionado aos cooperados, foi aplicado no mês de abril durante as visitas ao Aterro Municipal, onde a cooperativa possui um galpão no Eco-ponto do Estádio Lomanto Junior. Já a entrevista foi realizada no dia 23 de fevereiro de 2017, às 09:00 horas da manhã, no ponto de apoio da Cooperativa, que fica na feirinha do Bairro Brasil, com duração de cinquenta e três minutos e dezessete segundos, através de gravação, transcrição e análise com base no referencial.

Após a tabulação dos dados dos questionários a partir do excel e da transcrição da entrevista, os dados receberam tratamento qualitativo (em função do primeiro instrumento de coleta) e tratamento quantitativo (em virtude do segundo instrumento de coleta).

\section{Meio ambiente}

No Brasil, o Conselho Nacional do Meio Ambiente - CONAMA, tomando como base a resolução (306:2002), define o meio ambiente como o conjunto de condições, leis, influências e interações de ordem física, química, biológica, social, cultural e urbanística que permite, abrigam e regem a vida em todas as suas formas.

As questões ambientais ganharam grande visibilidade após a Conferência das Nações Unidas sobre Meio Ambiente e Desenvolvimento, Rio-92, também conhecida como ECO-92, época em que a discussão sobre os impactos do desenvolvimento nos ecossistemas e na saúde da população se popularizou, em virtude do excessivo uso dos recursos naturais, e não apenas dos impactos gerados pela população industrial, tendo em vista a escassez dos recursos.

Segundo Dias (2007), como produto desse encontro, foram assinados cinco documentos que direcionariam as discussões sobre o meio ambiente nos anos subsequentes, sendo eles:

- $\quad$ Agenda 21;

- $\quad$ Convênio sobre a Diversidade Biológica (CDB); 
- $\quad$ Convênio sobre as mudanças climáticas;

- $\quad$ Princípios para a gestão sustentável das florestas;

- Declaração do Rio de Janeiro sobre meio ambiente e desenvolvimento.

Dentre esses cincos documentos, destacamos a Agenda 21, uma das principais propostas da ECO-92 e uma grande iniciativa no caminho da implantação do desenvolvimento sustentável. Trata-se de um instrumento de planejamento para a construção de sociedades sustentáveis, em diferentes bases geográficas, que concilia métodos de proteção ambiental, justiça social e eficiência econômica. Existem três tipos de agenda, a global, que é assinada por todos os países e trata das políticas mundiais de crescimento sustentável, as agendas nacionais, que são feitas pelos governos federais e, por fim, as locais, elaboradas nas cidades pela própria população, todas com o mesmo objetivo: promover o desenvolvimento sustentável.

\section{Gerenciamentos de resíduos urbanos}

O gerenciamento dos resíduos sólidos, principalmente nos ambientes urbanos, é um importante mecanismo para o desenvolvimento socioeconômico e ambiental, que pode ser associado tanto à saúde da população quanto à proteção do meio ambiente. $\mathrm{Na}$ medida em que os resíduos não coletados ou dispostos em locais inadequados, favorecem a proliferação de vetores de doenças, bem como a contaminação do solo e águas. “A geração total de RSU, no Brasil, em 2014, foi de aproximadamente 78,6 milhões de toneladas, o que representa um aumento de 2,9\% de um ano para outro, índice superior à taxa de crescimento populacional no país no período, que foi de $0,9 \%$ " (ABRELPE, 2014, p.77). Isso significa que o consumo populacional por pessoa tem aumentado e, apesar de existir políticas para o desenvolvimento socioambiental, a maior parte do lixo produzido não é reaproveitada.

O desenvolvimento de políticas voltadas ao bem-estar ambiental, como a Lei $\mathrm{n}^{\circ}$ 12.305/10, que institui a Política Nacional de Resíduos Sólidos (PNRS), trata da prevenção na geração dos resíduos sólidos, bem como institui a responsabilidade compartilhada dos geradores de resíduos. Além disso, favorece o desenvolvimento social e ambiental e o desenvolvimento de planos de gestão dos resíduos para a redução de impactos sociais e ambientais. Entretanto, em se tratando da realidade brasileira, os 
agentes responsáveis pela gestão de resíduos não trabalham conjuntamente, evidenciando ainda mais a problemática.

Segundo a Dias (2007), cerca de 80 mil toneladas de resíduos sólidos urbanos são descartadas, diariamente, no Brasil de forma inadequada. Quantidade correspondente a mais de $40 \%$ do lixo coletado. Isso significa que quase metade dos lixos produzidos está dispersa no meio ambiente, trazendo problemas à saúde ambiental e à população, evidenciando a necessidade de efetivação das políticas públicas voltadas para o meio ambiente.

De acordo com a normativa da ABNT NBR 10004/2004, os resíduos sólidos são definidos como:

Resíduos sólidos: Resíduos nos estados sólido e semi-sólido, que resultam de atividades de origem industrial, doméstica, hospitalar, comercial, agrícola, de serviços e de varrição. Ficam incluídos nesta definição os lodos provenientes de sistemas de tratamento de água, aqueles gerados em equipamentos e instalações de controle de poluição, bem como determinados líquidos cujas particularidades tornem inviável o seu lançamento na rede pública de esgotos ou corpos de água, ou exijam para isso soluções técnica e economicamente inviáveis em face à melhor tecnologia disponível (ABNT, 2004, p. 7).

Para Garcia (2016), resíduos sólidos é todo material proveniente de atividades humanas nas indústrias, comércios e residências, considerados inúteis. Entretanto, grande parte deles pode ser reaproveitada através da coleta seletiva e reciclagem e ser revertida em lucro para empresas, meio ambiente e sociedade.

Ao observar essa problemática, implantou-se a Lei $\mathrm{n}^{\circ} 12.305 / 10$, que institui a Política Nacional de Resíduos Sólidos (PNRS), contendo instrumentos importantes para permitir o avanço necessário do país. Tal Lei reforça o enfrentamento dos principais problemas ambientais, sociais e econômicos, decorrentes do manejo inadequado dos resíduos sólidos.

O texto da PNRS também evidencia a gestão dos resíduos sólidos como uma das melhores alternativas para redução dos impactos ambientais, geração de emprego e renda. Para Strauch e De Albuquerque (2008, p. 103), “A gestão de resíduos é um fenômeno extraordinariamente complexo que tem aspectos sociais, econômicos, ecológicos e éticos". Tal posicionamento evidencia que, para que seja implantada uma gestão de resíduos sólidos, primeiro, é necessário conhecer a realidade local.

Destarte, o incentivo à maximização da reciclagem e do reaproveitamento dos resíduos, através do correto gerenciamento de resíduos sólidos, promovido 
conjuntamente pelos agentes responsáveis, além de gerar emprego, renda e contribuição socioambiental, minimiza a geração desses resíduos, cuja disposição final provoca sérios impactos sobre meio ambiente.

\section{Coleta seletiva}

A coleta seletiva, definida na Lei Federal $n^{\circ} 12.305 / 2010$, como a coleta de resíduos sólidos previamente separados de acordo com a sua constituição e composição, deve ser implementada por municípios como forma de encaminhar as ações destinadas à promoção do bem-estar social.

De acordo com a PNRS, a implantação da coleta seletiva é obrigação dos municípios, e algumas metas fazem parte do conteúdo mínimo que deve constar nos planos de gestão integrada de resíduos sólidos dos municípios. Aligleri et al. (2009, p.104) definem coleta seletiva e seus benefícios como

[...] recolhimento dos materiais que são passíveis de serem reciclado, previamente separados na fonte geradora. Dentre estes materiais recicláveis, encontram-se diversos tipos de papéis, plásticos, metais e vidros. A separação na fonte geradora evita a contaminação de materiais reaproveitáveis, aumenta o valor agregado destes e diminui custos de reciclagem. Também pode-se destacar como benefícios a diminuição da poluição do solo, da água e do ar; economia de energia e água; diminuição do lixo nos aterros e lixões e, consequentemente, nos gastos de limpeza urbana, bem como novas oportunidades de fortalecer cooperativas e gerar renda pela comercialização dos recicláveis.

Há anos a reciclagem é sustentada no Brasil por meio da catação informal. Sem condições favoráveis de trabalho, muitos indivíduos se submetiam e ainda se submetem à catação nas ruas ou nos "lixões", sem uma legislação que subsidiasse as atividades dos catadores. Hoje, existem programas formais de coleta seletiva, os quais são vantajosos para todos os agentes responsáveis ou interessados pela gestão de resíduos sólidos. Dentre diversas vantagens, a CEMPRE (2014, p. 06) destacam:

. Redução de custos com a disposição final do lixo (aterros sanitários e incineradores);

. Aumento da vida útil de aterros sanitários

- Diminuição de gastos com remediação de áreas degradadas pelo mau acondicionamento do lixo (por exemplo, lixões clandestinos); .

. Educação e conscientização ambiental da população;

- Diminuição de gastos gerais com limpeza pública, considerando-se que o comportamento de comunidades educadas e conscientizadas 
ambientalmente traduz-se em necessidades menores e intervenção do estado;

. Melhoria das condições ambientais e de saúde pública do município;

- Geração de empregos diretos e indiretos com instalação de novas indústrias recicladoras;

- Resgate social de indivíduos por meio da criação de associações e cooperativas de catadores.

Portanto, a coleta seletiva por catadores, atualmente, tem grande importância no abastecimento dos recicláveis e geralmente exige a construção de galpões de triagem onde os materiais recicláveis são recebidos e separados e deve estar baseada no tripé: tecnologia - para efetuar a coleta, separação e reciclagem; mercado - para absorção do material recuperado e conscientização - para motivar a população para contribuição.

\section{Cooperativismo}

Historicamente, o cooperativismo originou-se na Europa durante o período de industrialização, seguindo do modelo Rochdale de Manchester Inglaterra, em 1844, período de plena efervescência de movimentos políticos e econômicos que se multiplicavam na Europa Ocidental, em oposição às consequências práticas do liberalismo econômico. No Brasil, apenas na década do século XIX o Estado reconheceu o direito de associação aos cidadãos brasileiros. Abtich et al (2012, p. 3), definem o cooperativismo da seguinte forma:

Cooperativismo pode ser entendido como um instrumento de organização econômica da sociedade, caracterizando-se como uma forma de ajuda mútua através da cooperação e da parceria. A sociedade cooperativa é uma associação autônoma de pessoas unidas voluntariamente para satisfazer suas necessidades econômicas, sociais e culturais em comum, por meio de uma empresa de propriedade conjunta e de gestão democrática.

Portanto, para que haja o cooperativismo, é necessário ter uma visão compartilhada. A organização coletiva do trabalho é caracterizada por diversas práticas e formas organizacionais que têm por objetivo associar pessoas para produzir e reproduzir meios com base em relações de reciprocidade e igualdade.

Sobre a questão política nas cooperativas, Mesquita (2007) entende que a democracia participativa, referente aos cooperados brasileiros, precisa ser estabelecida de modo mais dinâmico e complexo. Isso porque a falta de educação política e cidadã 
O trabalho em cooperativas de reciclagem de resíduos sólidos: um estudo do Recicla Conquista SANTOS, A. M.; DANTAS, M. Z.; TEIXEIRA, S. S.

ainda é muito expressiva. O mesmo autor aponta que esse tipo de comportamento dos cooperados brasileiros não tem relação direta com o nível socioeconômico ou com o baixo nível de escolaridade, visto que abrange os brasileiros em todas as parcelas populacionais, porque em poucas instâncias da educação formal há formação sobre os instrumentos de participação política no país.

A partir da década de 1990, surgiram as primeiras ações de formação de cooperativas de catadores no Brasil, em resposta ao aumento significativo da população e inchaço urbano e, consequente, ampliação da geração de resíduos sólidos.

A formação de cooperativas de coleta seletiva vem crescendo no Brasil tanto pelos altos níveis de pobreza, que obrigam muitas pessoas a procurarem sobrevivência catando lixo, quanto pela quantidade crescente de lixo lançado pela população que detém o alto poder aquisitivo.

Essa forma de organização gera a economia da matéria-prima usada na produção de papel, plástico, alumínio, entre outros. Além disso, é importante mencionar que, em vários países em desenvolvimento, como o Brasil, a constituição das cooperativas pode ser entendida como uma estratégia de sobrevivência para pessoas excluídas do mercado de trabalho (DIAS, 2007). Para o mesmo autor, a disposição de catadores em formato de cooperativas permite a valorização e profissional, em relação ao trabalho do catador, bem como a inclusão social, o exercício da cidadania e a remoção dos catadores dos lixões e aterros (DIAS, 2007).

Compreendendo que a maioria das cooperativas não tem os recursos necessários para a coleta, bem como a separação dos resíduos sólidos, há, portanto, a necessidade de parceria com as prefeituras, a fim de conceber o desenvolvimento de tais cooperativas. Além disso, é importante que o governo municipal se disponibilize a colaborar com a localização, transporte, maquinários necessários, treinamento da mão de obra, entre outras providências necessárias para efetivação do trabalho das cooperativas.

\section{Cooperativa de Catadores Recicla Conquista}

A Cooperativa de Catadores Recicla Conquista LTDA, criada em 2004, é fruto de um trabalho de intervenção da Pangea. Segundo o Projeto de Formação, a Cooperativa tem a Missão de contribuir para o programa de combate à pobreza, por meio de ações de reciclagem e coleta seletiva, preservando o meio ambiente, gerando trabalho e renda, além de consolidar a auto-sustentabilidade.

GEOPAUTA, V. 2, no 1, 2018 http://periodicos2.uesb.br/index.php/geo 
A visão da Cooperativa é prestar o melhor serviço possível na área de coleta seletiva e reciclagem de materiais, sendo a melhor opção para os catadores de materiais recicláveis da região e baseia-se em valores cooperativistas de ajuda e responsabilidade próprias, como Ajuda Mútua e Responsabilidade, Democracia, Igualdade, Equidade, Solidariedade, Honestidade, Transparência, Responsabilidade Social.

Em entrevista ao coordenador da Cooperativa, ficou esclarecido que, atualmente, há uma direção eleita, composta exclusivamente de catadores cooperados, responsável pela administração da organização. A Cooperativa possui aproximadamente 40 cooperados, um caminhão, uma picape Strada e equipamentos necessários para realizar a coleta seletiva, triagem, prensagem e armazenagem de materiais recicláveis.

\section{Estrutura de funcionamento da Cooperativa}

Segundo a estrutura de funcionamento, o coordenador afirma:

A Cooperativa, hoje, gera em torno de 60 toneladas por mês; isso, em volume de recicláveis do município, não corresponde nem a $5 \%$ do lixo produzido. Se somar tudo que se produz de reciclagem dentro do município, incluindo aí os catadores autônomos e os atravessadores que recolhem também a totalidade de volume reciclado, chega a 30\%, ou seja, $70 \%$ do total de lixo produzido ainda não são recicláveis; então está indo muita coisa para o lixo sem ser utilizado, recurso que poderia estar sendo trabalhado, virando dinheiro. É necessário, portanto, que se crie uma prática de coleta seletiva para tentar resolver essa questão. Conquista, hoje, chega a produzir 320 toneladas de lixo por dia (Informação verbal, 2017) ${ }^{1}$.

Quando questionado sobre as principais dificuldades enfrentadas pela cooperativa, o coordenador destaca a separação dos materiais, visto que chegam muitos resíduos de diferentes tipos misturados; ou seja, a sociedade não faz nenhuma separação. Nas palavras dele:

não existe conscientização popular suficiente. Seria interessante se as pessoas separassem o material em casa, de modo que chegasse na cooperativa de uma maneira mais fácil de fazer triagem [...]. A sociedade não entende ainda o mecanismo de coleta seletiva como deveria; sabe que existe; sabe como fazer até porque é muito simples, mas não possui o hábito. Pouca gente faz coleta seletiva na cidade e

\footnotetext{
${ }^{1}$ Entrevista concedida pelo COORDENADOR DO RECICLA CONQUISTA, Entrevista I. [Fev. 2017]. Entrevistador: Aline Marinho Santos. Vitória da Conquista, 2017.
} 
O trabalho em cooperativas de reciclagem de resíduos sólidos: um estudo do Recicla Conquista SANTOS, A. M.; DANTAS, M. Z.; TEIXEIRA, S. S.

existe ainda o desvio de pensamento de que a responsabilidade é apenas do catador (Informação verbal, 2017) ${ }^{2}$.

Ele cita também os vários acidentes que ocorrem com os cooperados, em virtude da falta de Equipamentos de Proteção Individual (EPIs); evidencia que, quando a cooperativa dispõe desses materiais, os cooperados têm resistência ao uso. A partir dessa informação, foi feito um levantamento, através de um questionário direcionado aos próprios cooperados, conforme se observa no Gráfico 01 abaixo:

\section{Gráfico 1- Uso de Equipamentos de Produção Individual}

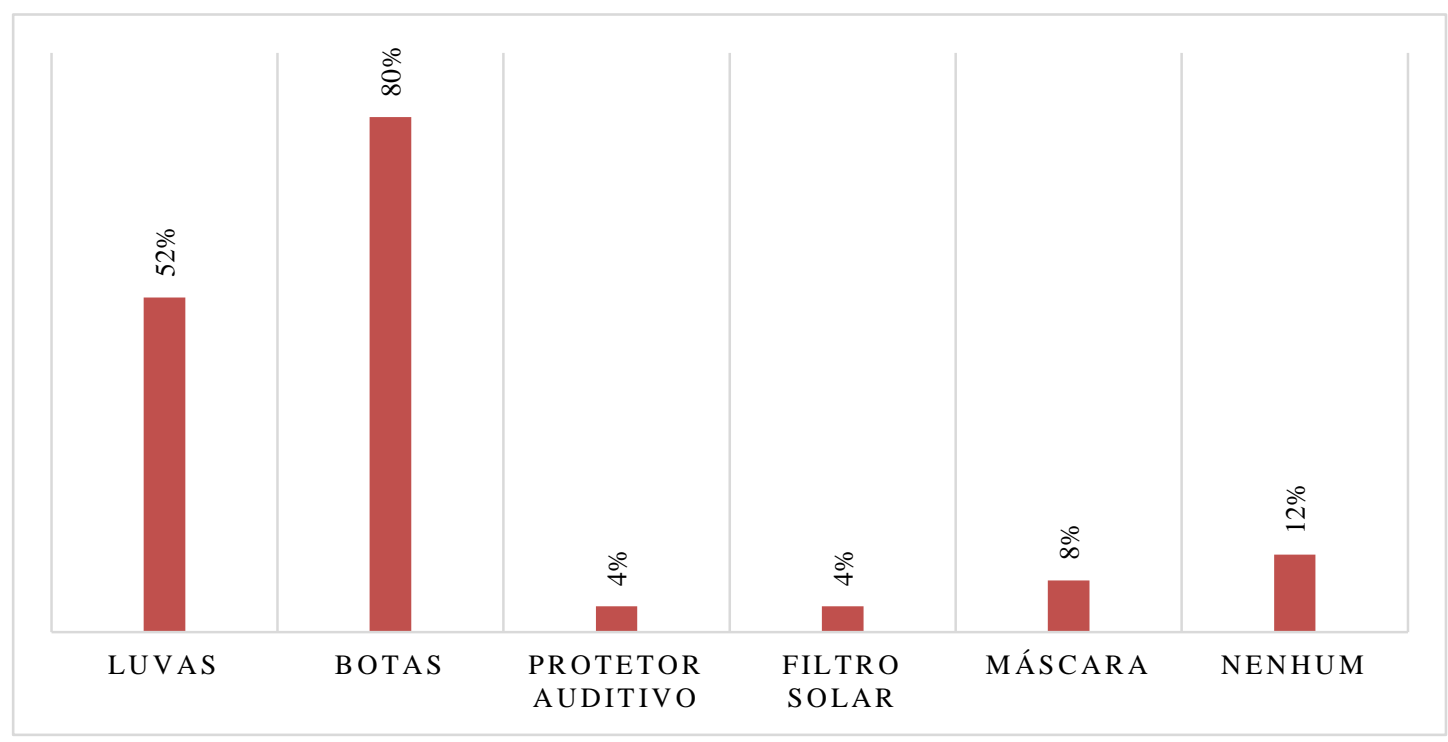

Fonte: Pesquisa de campo, 2017.

Sobre o uso de alguns Equipamentos de Produção Individual, foi verificado que $52 \%$ utilizam luvas, $80 \%$ usam botas. Entre outros dados, foi identificado que apenas $4 \%$ dos cooperados utilizam protetor auditivo e filtro solar (GRÁFICO 1). Essas informações confirmam o resultado da entrevista concedida pelo Coordenador da Cooperativa, que afirmou:

O fardamento vai completo, com bota, luva, protetor auricular para os cooperados que trabalham com prensa, óculos de proteção para os olhos, porém percebe que a prática do uso não é muito trabalhada. [...] muito catadores trabalham sem luva, sem bota; o uso da farda começa ser deixado de lado. Geralmente, eles usam quando iniciam o trabalho na Cooperativa, mas, conforme o tempo passa, eles deixam utilizar [...] (Informação verbal, 2017) ${ }^{3}$.

\footnotetext{
${ }^{2}$ Entrevista concedida pelo COORDENADOR DO RECICLA CONQUISTA, Entrevista 2. [Fev. 2017].

Entrevistador: Aline Marinho Santos. Vitória da Conquista, 2017.

${ }^{3}$ Idem p.34.

GEOPAUTA, V. 2, no 1, 2018 http://periodicos2.uesb.br/index.php/geo
}

Este é um artigo de acesso aberto sob a licença Creative Commons da CC BY 
Essa identificação vai de encontro com a afirmação dos autores Strauch e De Albuquerque (2008), os quais alertam que tirar pessoas do lixão e colocá-las em empresa de triagem não é algo fácil, pois muitos trabalhavam por conta própria e em condições insalubres e nem sempre entendem a necessidade do uso de fardas e equipamentos que trazem benefícios e segurança na realização do trabalho.

Sobre a percepção dos cooperados com relação à saúde e segurança promovida pela cooperativa, identificou-se que nenhum cooperado está muito satisfeito, pois $70 \%$ deles estão pouco satisfeitos, e $11 \%$ estão totalmente insatisfeitos. Esta informação reflete a ausência de educação, informação e formação Cooperativista, contrariando os princípios do cooperativismo, contidos na Agenda Institucional da OCB (2015), que traz como princípio basilar o dever de promover a educação e a formação dos seus membros, dos representantes eleitos e dos trabalhadores, de forma que esses possam contribuir eficazmente para o desenvolvimento do empreendimento, tendo os membros autonomia e independência.

Sobre as decisões tomadas na Cooperativa dos Catadores Recicla Conquista, $56 \%$ dos cooperados afirmaram ser adotadas pelo presidente, destoando dos sete princípios do cooperativismo, segundo a OCB (2015). Tais princípios afirmam que cada cooperado tem igual direito de participar ativamente das decisões políticas e administrativas da cooperativa (um membro, um voto), sendo que as tomadas de decisões devem ser direcionadas de forma conjunta, na forma de uma gestão democrática, o que reforça a necessidade de uma educação cooperativista.

Sobre a realização das assembleias gerais, necessárias ao bom funcionamento das cooperativas, $52 \%$ dos cooperados afirmaram que elas não acontecem. Essa informação não condiz com a Lei n. ${ }^{\circ}$ 5.764/71, a qual declara que nos três primeiros meses do ano após o término do exercício social, as cooperativas devem organizar as assembleias gerais ordinárias sobre os seguintes assuntos: prestação de contas dos órgãos de administração acompanhada de parecer do Conselho Fiscal, com relatório de gestão e balanço; demonstrativo das sobras apuradas ou das perdas decorrentes da insuficiência das contribuições para cobertura das despesas da sociedade, bem como eleições dos componentes do conselho de administração, do conselho fiscal e de outros, quando for o caso. E as assembleias gerais extraordinárias realizar-se-ão sempre que necessário e poderão deliberar sobre qualquer assunto de interesse da sociedade. 
O trabalho em cooperativas de reciclagem de resíduos sólidos: um estudo do Recicla Conquista SANTOS, A. M.; DANTAS, M. Z.; TEIXEIRA, S. S.

Quanto aos cursos que deveriam ser promovidos pela Cooperativa, 64\% dos cooperados afirmaram que eles não ocorrem. Sobre isso, o coordenador releva que aos novos cooperados, é explicado apenas qual será sua função. Para o coordenador, por se tratar de um trabalho braçal, não há necessidade de cursos específicos. Caso seja necessária alguma informação específica, é feita uma explicação rápida e informal.

$\mathrm{Na}$ entrevista, ao questionar sobre o Fundo de Assistência Técnica Educacional e Social (FATES), o qual, segundo o Manual de Orientação para constituição de cooperativas (1996), é um fundo de 5\% sobre as sobras e tem como objetivo ser revertido em uso do próprio dos cooperados através de cursos, palestras, para assistência educacional, de forma a capacitá-lo, o coordenador afirma não possuir.

Quando incitado a falar sobre os benefícios de se associar à Cooperativa, o coordenador evidencia que, na condição de cooperados, os trabalhadores são legalizados, têm função específica, e, portanto, têm acesso ao crédito; podem comprovar renda, ter cartão de crédito próprio, parcelar uma compra, benefícios que eles mesmos diziam não possuir.

Sobre a obtenção de bens após a entrada na cooperativa, apenas $24 \%$ dos catadores da Cooperativa afirmaram não ter obtido nada. Ou seja, 76\% dos cooperados adquiriram algum item após a entrada na cooperativa, dos quais, 52\% conseguiram adquirir TV; $24 \%$, fogão e geladeira; $20 \%$, máquina de lavar; $4 \%$, casa própria; $8 \%$, moto e $4 \%$ computador.

Quando questionado acerca das possíveis parcerias firmadas entre a Cooperativa e outras instituições e órgãos, o coordenador diz:

Temos parceiro, como o shopping, Hiper Bompreço, Maxxi Atacado, e várias concessionárias na cidade fornecem materiais recicláveis. Há também as parcerias sociais; grupos de apoio sempre promovem a conscientização, com palestras, educação ambiental, núcleo pedagógico e psicológico da Prefeitura para pessoas que tenham problema com alcoolismo, droga; é interessante e necessário, pois dão assistência e acompanha os cooperados. Os recursos para realização desse trabalho vêm de órgãos que financiam como Banco do Brasil, FUNASA, o BNDES, Petrobrás (Informaçao verbal, 2017) ${ }^{4}$.

Referente à venda dos materiais coletados o Coordenador explica que é feita por atravessadores. Segundo ele, o propósito inicial da Cooperativa era eliminar a presença desses indivíduos no processo de venda, inclusive, para garantir um maior

\footnotetext{
${ }^{4}$ Idem p.34.

GEOPAUTA, V. 2, no 1, 2018 http://periodicos2.uesb.br/index.php/geo
}

Este é um artigo de acesso aberto sob a licença Creative Commons da CC BY 
valor aos cooperados; porém, a Cooperativa é imediatista, e a pressão dos cooperados para receber o dinheiro de imediato é grande, fatos que inviabilizam o planejamento de venda. Nas palavras do Coordenador:

Já houve um período em que se vendeu direto para a indústria. $\mathrm{O}$ problema é que a indústria, depois de um determinado período de comercialização, propôs um mecanismo de pagamento que não foi aceito pelos cooperados, pois solicitava que fosse metade na retirada do material e o restante com a chegada desse material na empresa, o que dava um prazo de mais ou menos 15 dias entre um valor e outro; com um valor um pouco melhor do que é oferecido pelo atravessador (Informaçao verbal, 2017) $)^{5}$.

Diante do exposto, fica evidente a necessidade da educação dentro da cooperativa. De acordo com o Manual de Orientação para Constituição de Cooperativas (1996), o autocontrole é instrumento indispensável para alcançar à autogestão, pois o cooperador necessita conhecer a situação da sua cooperativa, para assumir as responsabilidades de sua função.

Outra dificuldade enfrentada pela Cooperativa, enumerada pelo Coordenador, refere-se ao não recolhimento do INSS. Nas palavras do coordenador: "infelizmente, eles não recolhem o INSS. já tentaram criar essa forma de contribuição dentro da cooperativa, só que eles não aceitam, pois acham alto o valor da contribuição.” Diante desta resposta, foi indagado se em algum momento aconteceu algum acidente de trabalho ou situação-problema que afastou o cooperado do trabalho. Sobre esse aspecto, o coordenador informou que: "[...] o estatuto prevê que, no caso de licença desse cooperado, observada a necessidade dos ganhos mensais, ele recebe atestado ou afastamento temporário em função de doença. A cooperativa entende que tem de pagar e é pago. O mesmo ocorre no caso de gravidez. Exclusas essas ocorrências, os cooperados afastados não recebem".

Ao ser indagado sobre se a autogestão da Cooperativa, o Coordenador relatou que se trata de uma utopia.

Não funciona, pelo menos de forma particular, na Cooperativa Recicla Conquista. Fica evidente, portanto, a necessidade de uma equipe gestora por trás, pelo menos para auxiliar na parte documental, assessoria e assistência, mesmo na parte administrativa, porque na

\footnotetext{
${ }^{5}$ Ibid. p.34.

GEOPAUTA, V. 2, no 1, 2018 http://periodicos2.uesb.br/index.php/geo
}

Este é um artigo de acesso aberto sob a licença Creative Commons da CC BY 
tentativa de deixar a gestão para os cooperados, vários erros começaram surgir (Informação verbal, 2017) .

O Entrevistado acrescenta:

\begin{abstract}
A mentalidade do catador é muito individual, então ele sai de uma realidade onde ele trabalhava de forma independente no lixão, não respondia a ninguém pelo que ele fazia e quando ele passa a ter um novo mecanismo de trabalho, a trabalhar de forma cooperativa, em que o esforço coletivo vai gerar o seu salário, no final do mês ele percebe que há pessoas que trabalham menos do que ele e ganham as mesmas coisas, porque a divisão tende a ser igual.

A parte documental, durante um bom momento, era feita pela equipe técnica, hoje a parte da divisão dos valores, pagamento de contas, uso do dinheiro para despesas é responsabilidade dos cooperados, com auxílio na parte técnica, documental, contábil, licenciamento ambiental, mas autogestão, que não funciona, fica na mão deles, pois, não tem fluxo de caixa, não tem nenhum controle; os cooperados não sabem o real objetivo da cooperativa, só vende, recebe o valor e divide (Informação verbal, 2017) ${ }^{7}$
\end{abstract}

Diante das considerações pontuadas na entrevista, observa-se que a dificuldade de mudança de pensamento dos cooperados em fazer a autogestão funcionar é um problema que interfere diretamente na gestão da Cooperativa. Além disso, a inércia dos agentes responsáveis pela gestão pública, em especial a sociedade, em colaborar com pequenos atos, como a separação domiciliar dos resíduos, dificulta ainda mais o trabalho dos cooperados, evidenciando a necessidade de implementação de programas de educação ambiental.

\title{
Considerações finais
}

A presente pesquisa possibilitou refletir a respeito do trabalho realizado na Cooperativa dos Catadores Recicla Conquista segundo a percepção dos cooperados.

Neste sentido, a partir dos resultados da análise realizada através de um questionário direcionado aos cooperados e de uma entrevista ao coordenador do Recicla Conquista, foi possível inferir que, apesar de a cooperativa ter um papel importante para o meio ambiente e para sociedade, ser fonte de renda para várias famílias e contribuir

\footnotetext{
${ }^{6}$ Id. p. 34 .

${ }^{7}$ Ibid. p. 34

GEOPAUTA, V. 2, no 1, 2018 http://periodicos2.uesb.br/index.php/geo
}

Este é um artigo de acesso aberto sob a licença Creative Commons da CC BY 
O trabalho em cooperativas de reciclagem de resíduos sólidos: um estudo do Recicla Conquista SANTOS, A. M.; DANTAS, M. Z.; TEIXEIRA, S. S.

para o meio ambiente através da reutilização dos resíduos, apresenta as dificuldades não apenas com a gestão dos resíduos sólidos, mas com a precária autogestão e aos princípios cooperativistas, que são deixados de lado.

Os resultados revelaram que a Cooperativa não possui fundo de reserva para reparar danos e perdas do exercício e contribuir para o desenvolvimento das atividades, quando danifica algum equipamento. Além disso, não tem nenhum tipo de Previdência, nem fundos que garantam direitos trabalhistas, tais como férias, décimo terceiro ou acidente de trabalho, sendo respaldados apenas pelo estatuto em caso de gravidez e acidentes.

Verificou-se que o dimensionamento do trabalho realizado pela Cooperativa não é insuficiente para a demanda vigente, já que a cidade está inserida nas estatísticas da PNUD (2015) cuja assertiva diz que cerca de 80 mil toneladas de resíduos sólidos urbanos são descartadas diariamente no Brasil, de forma inadequada. Tal informação corresponde a mais de $40 \%$ do lixo coletado, isso significa que quase metade do lixo produzido está disperso no meio ambiente, o que acarreta diversos problemas ambientais e consequentemente afeta a saúde da população.

É fundamental destacar que um dos meios para o reaproveitamento do ciclo reverso do produto descartado é a reciclagem, porém é importante que ela seja percebida em toda sua complexidade, e não apenas como única e inquestionável alternativa. Pensando assim, o principal enfoque da reciclagem como instrumento para combate a crise ambiental deve se dá muito menos pelo ponto de vista do esgotamento de recursos, da economia, de energia ou redução de impactos. Assim sendo, seu grande valor está no potencial de sensibilização e mobilização dos indivíduos em relação à necessidade de desenvolver uma visão crítica dos processos de produção e consumo.

\section{Referências}

ABCIHT, Alexandre de Melo et al. O valor da marca sicredi: uma análise na cooperativa do Vale do Rio Pardo- RS. In: XV SEMEAD Seminários em administração, 2012. Disponível em: < http://sistema.semead.com.br/15semead/resultado/trabalhosPDF/871.pdf>.

ALIGLERI, Lilian; ALIGLERI, Luiz Antonio; KRUGLIANSKAS, Isak. Gestão socioambiental: responsabilidade e sustentabilidade do negócio. São Paulo: Atlas, 2009. 
O trabalho em cooperativas de reciclagem de resíduos sólidos: um estudo do Recicla Conquista SANTOS, A. M.; DANTAS, M. Z.; TEIXEIRA, S. S.

ABNT - Associação Brasileira de Normas Técnicas. NBR 10004:2004 - Resíduos sólidos - classificação. Rio de Janeiro, 2004.

Associação Brasileira de Empresas de Limpeza Pública e Resíduos Especiais (Abrelpe). Panorama de Resíduos Sólidos no Brasil- 2014. São Paulo: Abrelpe; 2014.

DIAS, Reinaldo. Gestão ambiental: responsabilidade social e sustentabilidade. São Paulo: Atlas, 2007.

GARCIA, Marcio Barreto Santos et al. Resíduos sólidos: responsabilidade compartilhada. Semioses, Bonsucesso v. 9, n. 2, p. 77-91, 2016.

MESQUITA JÚNIOR, José Maria de. Gestão integrada de resíduos sólidos. Coordenação de Karin Segala. Rio de Janeiro: IBAM, 2007.

OLIVEIRA, Ana Paula da Costa. A participação do consumidor-gerador de resíduos e sua contribuição no instrumento da coleta seletiva prevista na política nacional de resíduos sólidos. In: Anais do Congresso de Ensino, Pesquisa e Extensão da UEG (ISSN 2447-8687). 2016.

OCB. Orientação para constituição de cooperativas conforme a nova nomenclatura do sistema OCB. $6^{\circ}$ edição revisada e ampliada. Brasília, 1996.

PNRS- Política Nacional de Resíduos Sólidos: contexto e principais aspectos.

Disponível em: < http://www.mma.gov.br/cidades-sustentaveis/residuossolidos/politica-nacional-de-residuos-solidos/contextos-e-principais-aspectos $>$. Acesso em 21 de julho de 2016.

PNUD. Programa das Nações Unidas para o Desenvolvimento. No Brasil, 80 mil toneladas de resíduos sólidos são descartados de forma inadequada por dia. Disponível em: < https://nacoesunidas.org/no-brasil-80-mil-toneladas-de-residuossolidos-sao-descartados-de-forma-inadequada-afirma-onu/ >. Acesso em: 21 de julho de 2016

STRAUCH, Manuel; ALBUQUERQUE, Paulo Peixoto de. Resíduos: como lidar com recursos naturais. Oikos, 2008.

ZANETI, Izabel Cristina Bruno Bacellar. Educação ambiental, resíduos sólidos urbanos e sustentabilidade: um estudo de caso sobre o sistema de gestão de Porto Alegre, RS. 2016. Tese (Doutorado em Desenvolvimento Sustentável) Universidade de Brasília, Brasília, 2003.

Recebido em: 20/03/2018

Aceito para publicação em: 30/04/2018 